\title{
约 \\ PANDEMIA DE COVID-19 NO RIO GRANDE DO SUL: O CHOQUE EXÓGENO GEROU MUDANÇAS NA AÇÃO DO PODER LEGISLATIVO?
}

\author{
COVID-19 PANDEMIC IN RIO GRANDE DO SUL: EXOGENOUS SHOCK \\ GENERATED CHANGES IN THE ACTION OF LEGISLATIVE POWER?
}

\section{PANDEMIA COVID-19 EN RIO GRANDE DO SUL: ¿GENERÓ EL CHOQUE EXÓGENO CAMBIOS EN LA ACCIÓN DEL PODER LEGISLATIVO?}

\author{
Lidia Nicole Ten Cate ${ }^{1}$ \\ Lucas dos Santos Giacomel ${ }^{2}$ \\ Maria Paula Escobar Bins ${ }^{3}$ \\ Pedro Cemim ${ }^{4}$ \\ Sara Epitácio 5 \\ Stéphani Schuetz Ramos ${ }^{6}$
}

\begin{abstract}
Resumo: O presente estudo tem como escopo a análise da atuação legislativa a partir do início do surto do novo coronavírus - Covid-19 no Rio Grande do Sul. Por meio de análise de conteúdo das proposições em tramitação pela Assembleia Legislativa do Estado do Rio Grande do Sul (ALRS) durante os primeiros meses do cenário pandêmico, a pesquisa buscou identificar padrões de taxas de sucesso e áreas de proposição em relação aos projetos. Os achados foram contextualizados com a situação regional e com considerações prévias da literatura. De acordo com as análises, a dinâmica da Assembleia Legislativa não sofreu mudanças significativas no contexto pandêmico inicial. Observou-se, assim, a manutenção do poder de agenda do Executivo e estabilidade de atuação pelos partidos, tanto da base governista, quanto da oposição.
\end{abstract}

Palavra-chave: Produção Legislativa; Poder Legislativo; Relações Entre Poderes; Covid-19; Pandemia.

Abstract: The present study aimed to analyze the legislative performance from the beginning of the outbreak of the new coronavirus - Covid-19 in Rio Grande do Sul. Through content analysis of the proposals being processed by the Legislative Assembly of the State of Rio Grande do Sul (ALRS) during the first months of the pandemic scenario, the research sought to identify patterns of success rates and areas of proposition in relation to projects. The findings were contextualized with the regional situation and with previous considerations in the literature. According to the analyzes, the dynamics of the Legislative Assembly did not undergo significant changes in the initial pandemic context. Thus, it was

\footnotetext{
${ }^{1}$ Graduanda em Políticas Públicas pela Universidade Federal do Rio Grande do Sul (UFRGS).

${ }^{2}$ Mestrando em Políticas Públicas pela Universidade Federal do Rio Grande do Sul (UFRGS). Especialista em Gestão Pública e Desenvolvimento Regional pela Universidade Federal de Pelotas (UFPEL).

${ }^{3}$ Doutoranda em Políticas Públicas pela Universidade Federal do Rio Grande do Sul (UFRGS). Mestre em Ciência Política pela Universidade de Lisboa (ULISBOA).

${ }^{4}$ Mestrando em Políticas Públicas pela Universidade Federal do Rio Grande do Sul (UFRGS).

${ }^{5}$ Professora adjunta da Universidade Federal do Pampa (UNIPAMPA). Pós-doutoranda em Políticas Públicas pela Universidade Federal do Rio Grande do Sul (UFRGS). Doutora em Ciência Política pela Universidade Federal do Rio Grande do Sul (UFRGS).

${ }^{6}$ Graduanda em Políticas Públicas pela Universidade Federal do Rio Grande do Sul (UFRGS).
} 
observed the maintenance of the Executive's agenda power and stability of action by the parties, both from the governing base and from the opposition.

Keywords: Parliamentary Production; Legislative Power; Relations among Branches of Government; Covid-19; Pandemic.

Resumen: El presente estudio tuvo como objetivo analizar el desempeño legislativo desde el inicio del brote del nuevo coronavirus - Covid-19 en Rio Grande do Sul. A través del análisis de contenido de las propuestas en trámite por la Asamblea Legislativa del Estado de Rio Grande do Sul (ALRS) durante los primeros meses del escenario pandémico, la investigación buscó identificar patrones de tasas de éxito y áreas de propuesta en relación a los proyectos. Los hallazgos se contextualizaron con la situación regional y con consideraciones previas en la literatura. Según los análisis, la dinámica de la Asamblea Legislativa no sufrió cambios significativos en el contexto inicial de la pandemia. Así, se observó el mantenimiento del poder de agenda del Ejecutivo y la estabilidad de la acción de los partidos, tanto desde la base gobernante como desde la oposición.

Palabras clave: Producción Legislativa; Poder Legislativo; Relaciones entre Poderes Gubernamentales; Covid-19; Pandemia.

\section{Introdução}

A pandemia ocasionada pelo novo coronavírus - Covid-19 - é apontada como uma das maiores crises vivenciadas no último século, comparada a momentos pós-guerra e superando, em termos de impacto, a "Grande Crise" de 1929 (SCHNEIDER, 2020). Tal acontecimento mobiliza a comunidade científica a analisar suas consequências nas mais diversas áreas do conhecimento.

No âmbito da Ciência Política e áreas correlatas, desafios de tal magnitude podem ser considerados como um choque exógeno, ou seja, um evento vindo de fora do próprio sistema e que tem grandes efeitos sobre a economia e/ou política (BLANCHARD, 2011). Alguns achados dessa estão relacionados à forma com que os desastres afetam incumbentes, e como estes são responsabilizados e punidos eleitoralmente por eventos críticos. Choques exógenos podem contribuir para desestabilizar regimes democráticos não consolidados, ou ainda, explicitar problemas de condução política que ganham relevância em momentos de calamidade. Uma visão menos catastrófica indica a possibilidade de tais contextos oferecerem atalhos para que transições para a democracia ocorram sem apelo revolucionário, e conduzidos por uma elite (AMAT; ANDREU; ARENAS; FALÓ-GIMENO; MUÑOZ, 2020).

No caso da Covid-19, as análises ainda recentes sinalizam para o aprendizado institucional propiciado pela pandemia, que exigiu respostas políticas rápidas e eficazes para o contingenciamento do vírus e, por outro lado, expôs dilemas sobre os princípios fundamentais que moldam nossos sistemas políticos (JANSEN; VOOR, 2020). Afinal, sistemas unitários foram mais ágeis e eficientes que sistemas federativos na contenção da pandemia? A busca por reposta a essa questão ressalta os dilemas de coordenação, a formação de consensos e o papel dos atores políticos nas distintas esferas políticas (WEIBLE, 2020; COCKERHAM; CREW, 2020). 
De todo modo, o contexto em questão pode ter representado uma "janela de oportunidades"7 para que mudanças em andamento fossem aceleradas. Ao analisar a atuação do congresso norte-americano nos meses subsequentes à declaração do Estado de emergência, Johnson e Marchant (2020) destacam as mudanças ocorridas no processo legislativo dos Estados Unidos. Em contextos normais, o Congresso norte-americano é caracterizado por certa inércia diante das inúmeras demandas por mudanças políticas e estatutárias. Mesmo sobre temas não polarizados politicamente e com estabilidade na formação de consensos, é impossível que o legislativo atue sobre todos os temas importantes. Tal inércia apenas é interrompida em casos de choques exógenos em que "janelas de oportunidades" são abertas e atores políticos adeptos a mudanças agem para lançar questões pertinentes a suas agendas. A pandemia pode ser apontada como um desses momentos.

O objetivo desse artigo é avaliar se, no caso brasileiro, a pandemia ocasionada pela Covid-19 agiu como um choque exógeno e alterou a relação entre os poderes legislativo e executivo. Para tanto, analisa-se a ação da Assembleia Legislativa do Rio Grande do Sul (ALRS) no enfrentamento inicial à pandemia. Pretendeu-se observar se diante desse novo cenário houve mudanças significativas na forma e conteúdo da ação parlamentar, bem como sua relação com o Executivo. Para isso, primeiramente, apresenta-se uma breve explanação, com base na literatura, sobre o perfil da ALRS, com destaque para composição partidária, relação com o Executivo e a taxa de sucesso sobre as proposições apresentadas. Na segunda parte, analisa-se parte das ações e impactos iniciais relacionados à pandemia para o Executivo e o Legislativo do RS, verificando brevemente como diferentes Estados lidaram com este evento. Em seguida, apresentamos uma classificação das proposições entre os meses de março a junho de 2020, com destaque para a origem - se de iniciativa do Executivo ou Legislativo - e o tipo de tramitação. Por fim, traçamos algumas considerações sobre os achados do estudo, que reforçam a manutenção da agenda do Executivo nos quatro meses analisados.

\section{O poder legislativo no estado do Rio Grande do Sul}

A literatura sobre a ação do Legislativo e Executivo nos Estados é influenciada por estudos sobre o congresso brasileiro. Em síntese, os principais achados sinalizam para o protagonismo dos Executivos estaduais na definição da agenda política (ABRUCIO, 1998; SOUZA, 1999; SANTOS, 2001), embora a capacidade de proposição e execução de políticas

\footnotetext{
${ }^{7}$ Para Kingdon (2003), a decisão nas políticas públicas ocorre a partir da confluência de três fluxos. O primeiro refere-se ao problema, momento em que o tema é colocado em questão. O segundo é o fluxo de políticas, momento em que a solução para o problema está disponível. O terceiro, o fluxo político refere-se a situações em que tanto motivação, quanto recursos para resolver um problema estão disponíveis. (FIGUEROA, 2018).
} 
públicas de maior envergadura encontrar-se vinculada a uma ação efetiva do Executivo Federal (FIGUEIREDO; LIMONGI, 1998; SANTOS, 1997). No entanto, percebe-se um aumento significativo do protagonismo do Congresso em relação a produção daquele, destacando a resposta à crise do Covid-19 (ALMEIDA, 2014, 2015).

Em contrapartida, o Legislativo no âmbito subnacional apresenta diversidade institucional (ANASTASIA, 2001), que permeiam os arranjos institucionais e as dinâmicas entre deputados e governadores. Essa assimetria torna-se evidente em estudos que abordam o desempenho e a produção legislativa (TOMIO; RICCI, 2012), o sistema partidário e a formação de coalizões (GROHMANN, 2001; NUNES, 2011; OLIVEIRA, 2018, 2016b), o processo decisório e a governabilidade (NUNES, 2013; OLIVEIRA, 2016a; TOMIO, 2005), a participação política e controle social (QUINTÃO; CUNHA, 2018; ZORZAL; CARLOS, 2017), o perfil da atuação dos deputados (PRATTI; ARAÚJO, 2019; FERREIRA; MENEGUIN; BUGARIN, 2018).

Entender esta diversidade institucional, bem como as dinâmicas existentes nestes poderes, especialmente no contexto da Assembleia Legislativa do Rio Grande do Sul (ALRS), ajuda a compreender não apenas a sua reação em situações atípicas, como a da pandemia de Covid-19, mas também observar seu funcionamento e suas especificidades. Historicamente, os deputados gaúchos demonstram domínio no volume de proposições apresentadas, em contrapartida, o governo domina o sucesso das proposições, apresentando altas taxas de sucesso em relação ao Legislativo (TOMIO; RICCI, 2012). Tal padrão justifica-se, em parte, pelo poder de agenda do Executivo, (FIGUEIREDO; LIMONGI, 1999); no entanto, não explicam por si só os baixos percentuais de sucesso do Legislativo.

O sucesso das proposições pode estar associado à existência de coalizões de apoio ao governo, que disciplinem as negociações e acordos entre governador e deputados (TOMIO e RICCI, 2012; NUNES, 2013). A Assembleia gaúcha historicamente, apresenta um subsistema partidário forte e estruturado ideologicamente, com expressiva diversidade de agremiações, que se agrupam em polos antagônicos, representados por partidos de esquerda e direita (GROHMANN, 2001; OLIVEIRA, 2016b). Nesse sentido, a governabilidade do Executivo depende, em parte, da formação de coalizões; estas, no caso da ALRS, formam-se a partir de coligações eleitorais, que são ampliadas por acordos partidários (NUNES, 2011; LUZ; AFLALO; DUTRA, 2018). Apesar disso, a força dessa polarização na ALRS torna-se evidente ao observar que, entre 1994 e 2014, nenhum partido desses dois polos participaram de coligações ou de coalizões do polo antagônico (OLIVEIRA, 2016b).

Para além das dinâmicas partidárias, a análise do conteúdo das proposições apresentadas pelos deputados evidencia a forma com que essas proposições impactam o Estado. Nesse sentido, no intuito de categorizar as proposições apresentadas no Legislativo, Ricci (2002) propõe tipologias para as leis, considerando a distribuição de benefícios pelo número de 
indivíduos interessados e pela dimensão territorial. No contexto da ALRS, evidencia-se que as proposições apresentadas pelos deputados contemplam, na sua maioria, o Estado como um todo, sinalizando para eventuais eleitores que não estão concentrados geograficamente em determinada região ou município (GROHMANN, 2001; TOMIO; RICCI, 2012).

Desta forma, a literatura permite conhecer os principais aspectos do Legislativo do RS, evidência diferentes padrões nas dinâmicas da assembleia, com destaque para a produção legislativa, as dinâmicas partidárias e o conteúdo das proposições. Para que seja possível identificar se tais padrões dialogam com o contexto atual da assembleia durante o combate a pandemia de Covid-19, a tabela 1 faz uma breve caracterização da atual legislatura $\left(55^{\text {a }}\right.$ Legislatura).

Tabela 1 - Distribuição partidária 55ª Legislatura

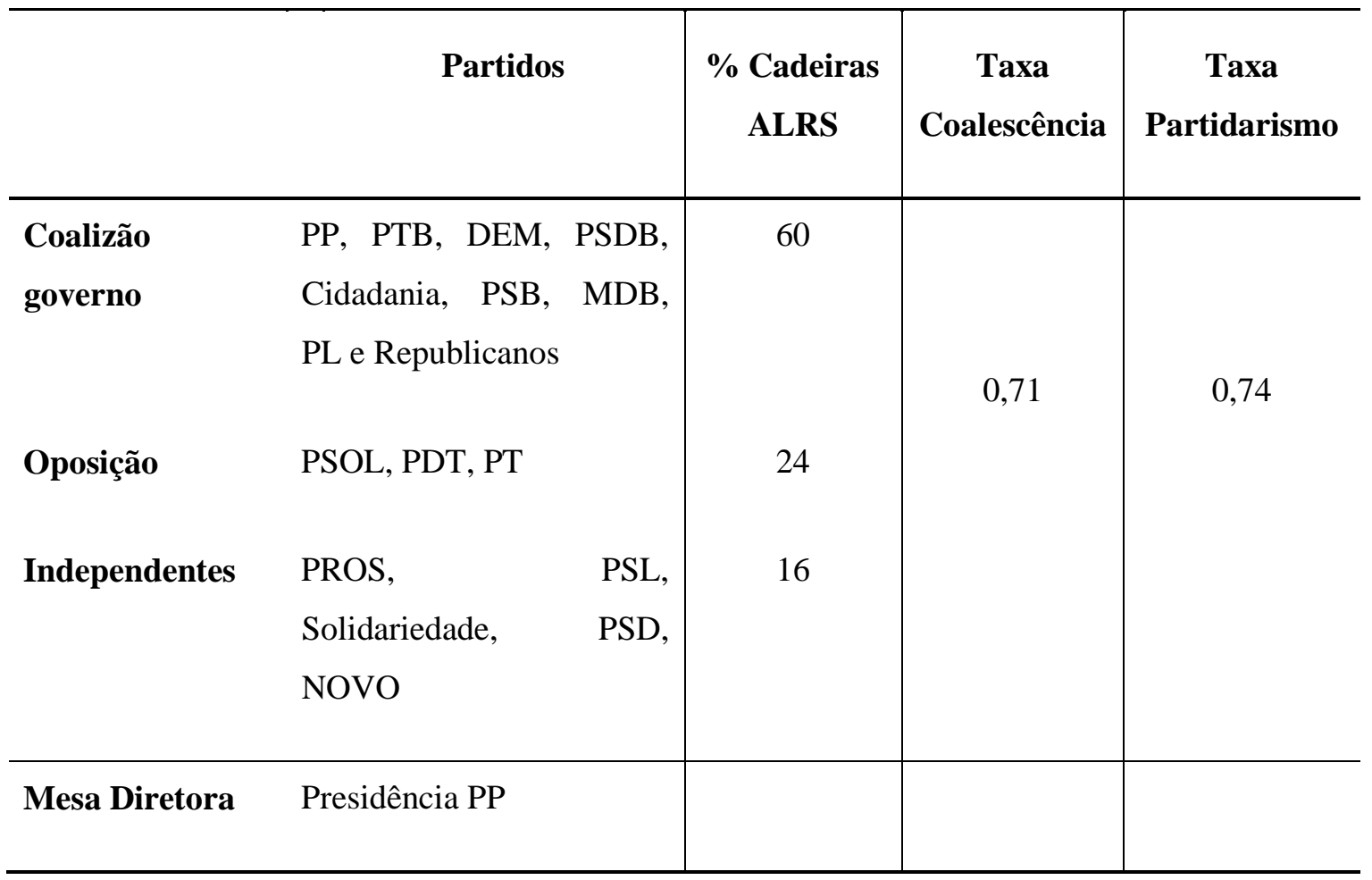

Fonte: Elaboração própria a partir dos dados da ALRS.

Nesse sentido, o atual Legislativo do RS é composto pela coalizão ${ }^{8}$ do governo Eduardo Leite (PSDB), representando 60\% do contingente legislativo e os $40 \%$ restantes são compostos por partidos de oposição e partidos autodeclarados independentes representando, respectivamente, $24 \%$ e $16 \%$ do contingente legislativo. Esse contexto ilustra a necessidade do governo em negociar cargos nas secretarias para obter apoio legislativo na implementação da agenda (NUNES, 2013). A taxa de coalescência do gabinete $(0,71)$ revela que há uma alocação

\footnotetext{
${ }^{8}$ Coalizão considera os partidos que detêm secretarias.
} 
relativamente proporcional entre as secretarias e o peso legislativo dos partidos. A taxa de partidarismo $(0,74)$, complementar à taxa de coalescência, revela que a proporção de secretários com apoio partidário no Legislativo também é alta. Esses indicadores poderiam explicar, em parte, a sustentação política e o nível de apoio dos deputados ao governo Eduardo Leite.

Cabe ressaltar que o partido da presidência da mesa diretora atual compõe a coalizão do governo, que possui a maioria do contingente legislativo, aspecto que, segundo Nunes (2013), aumenta a probabilidade de aprovação de proposições que não imponham custos concentrados a nenhum dos atores, o que pode contribuir no momento de propor ações para combater à pandemia. Em um segundo momento a nossa análise se concentra em quais são as questões que a pandemia tem trazido para o sistema federativo brasileiro, verificando como diferentes estados e legislativos lidaram com a chegada desta.

\section{Covid-19 no estado do Rio Grande do Sul}

Observando as medidas implementadas pelo Poder Executivo, o Estado do Rio Grande do Sul criou atividades coordenadas para combater o avanço da pandemia antes mesmo de haver o primeiro caso de infectado no Estado. A primeira ação do governo foi a criação do Centro de Operações Emergências (COE), feita dois dias antes da declaração da Organização Mundial da Saúde (OMS) de que o avanço do novo coronavírus constituiu emergência em saúde pública de importância internacional. Após essa ação, em fevereiro, foi lançado o Plano de Ação e Contingência com a finalidade de preparar o monitoramento, controle e assistência de casos que viessem a acontecer no Estado. O primeiro caso confirmado de Covid-19 no RS ocorreu no dia 10 de março de 2020 e, a partir desta data, o governo decretou medidas temporárias de prevenção, recomendando a suspensão de atividades não essenciais durante 30 dias - o que posteriormente foi prorrogado.

Assim como o Poder Executivo Estadual se articulou para amenizar os danos causados pelo Covid-19, a Assembleia Legislativa do Rio Grande do Sul também apresentou ações tempestivas: cita-se a aprovação, por unanimidade, de dois projetos de lei encaminhados pelo Executivo para ampliar o combate ao novo coronavírus no Estado. Além disto, promoveu adaptações sua dinâmica interna, alterando o horário de funcionamento e reduzindo o número de circulação de pessoas em seu ambiente, ao tempo em que manteve serviços essenciais e suspendeu - em um primeiro momento - as plenárias que posteriormente passaram a ser realizadas no formato online.

Essas medidas de restrições das atividades foram observadas em outros Estados do país, como São Paulo, Santa Catarina, Paraná e Mato Grosso do Sul. Porém, diferente de outros casos observados, no Rio Grande do Sul ocorreu uma expansão do número de contaminados e dos 
óbitos, resultantes das medidas de relaxamento do isolamento social e da flexibilização do comércio realizada pelo governo a partir do dia 16 de abril (MAYER, 2020).

Porém, além dessa diferença, algumas semelhanças podem ser destacadas: o protagonismo dos Executivos em todo país, a dificuldade de coordenação centralizada derivada do sistema federativo brasileiro, o que em alguns casos agravou o cenário de propagação do vírus, a ineficiente distribuição de equipamentos de saúde para os municípios, além é claro de pressão do setor empresarial para flexibilização das medidas de isolamento social (SANTANA; PEREZ, 2020).

\section{Métodos e Análise de Resultados}

\subsection{Metodologia}

Por meio de uma análise descritiva da produção legislativa durante os quatro meses iniciais do surto do Covid-19 - março a junho -, a pesquisa buscou compreender a dinâmica da Assembleia Legislativa do RS no período. Para tanto, foram mapeadas as proposições legislativas ocorridas, analisando seu conteúdo em relação a pandemia. Desta forma, busca-se analisar o posicionamento e as reações do parlamento gaúcho a partir do choque exógeno.

O estudo considerou os PLs, PLCs, PDLs, PECs e PRs ${ }^{9}$ pautados entre o intervalo de 19/03/2020 a 30/06/2020. Para a avaliação quanto à tramitação dos projetos, expandiu-se a data de consulta para 06/08/2020 como limite da análise, permitindo maior detalhamento quanto ao andamento das proposições e a verificação da taxa de sucesso nas aprovações até a data informada. A extração dos dados ocorreu diretamente do site da ALRS. Após o levantamento, foi realizada uma etapa de leitura das justificativas e do texto-lei, permitindo classificar as proposições em "Covid-19" e "outros temas". Adicionalmente, para melhor detalhamento das relacionadas à pandemia, optou-se por realizar categorização em cinco tipologias, baseadas no tema predominante: i) medidas de prevenção; ii) profissionais da saúde; iii) proteção social; iv) setor privado; e v) administrativo.

\subsection{Análise de resultado: produção legislativa durante a pandemia}

A pesquisa buscou compreender as diferentes características dos projetos em relação a seus proponentes e seu conteúdo, assim como a relação do Executivo e Legislativo durante os primeiros meses da pandemia. As proposições apresentadas na Assembleia são evidenciadas na

\footnotetext{
${ }^{9}$ As referências utilizadas pela ALRS são as seguintes: PL - Projeto de lei; PLC - Projeto de lei complementar; PDL - Projeto de decreto legislativo, PEC - Proposta de emenda à constituição; PR - Projeto de resolução.
} 
Figura 1 que apresenta as proporções de projetos relacionados à pandemia tramitados na ALRS, em relação ao total de projetos.

Figura 1 - Projetos pautados na ALRS de acordo com poder proponente

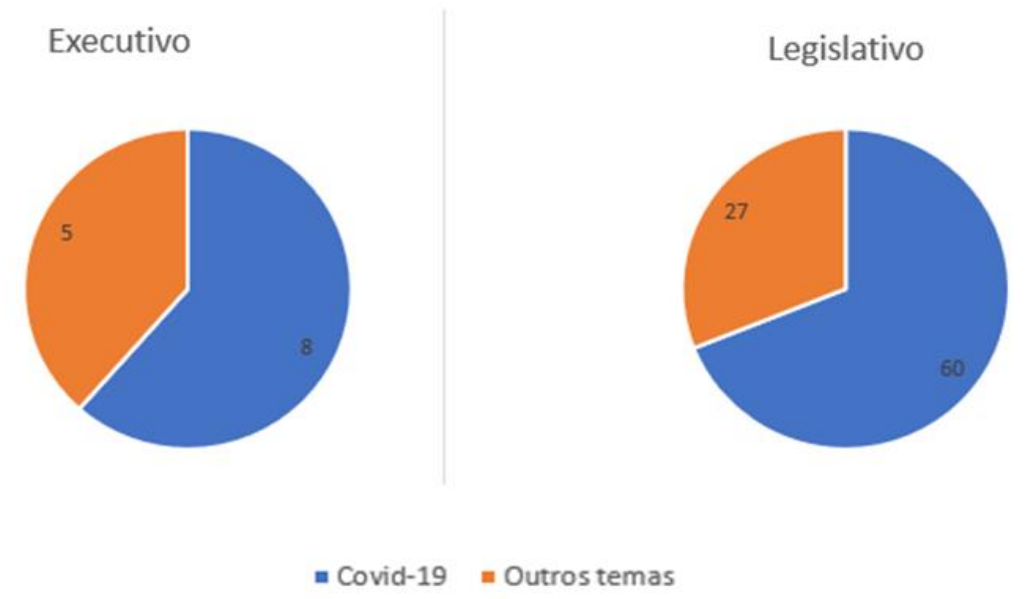

Fonte: Elaboração própria a partir dos dados da ALRS.

A atuação da ALRS no período analisado apresenta priorização no encaminhamento de matérias com relação direta ao Covid-19, observando-se que $68 \%$ das proposições estiveram diretamente relacionadas a esta matéria. Dentre os fatores explicativos, destaca-se o regramento normativo de atuação da assembleia, onde as proposições encaminhadas no intervalo entre 22/04/2020 e 20/05/2020 estiveram restritas àquelas relacionadas ao combate da disseminação do Covid-19.

Ao analisar o total de proposições, 13\% foram apresentadas pelo Poder Executivo e, dessas, 8 possuem relação com o Covid-19 e 5. Paralelo, as proposições apresentadas pela Assembleia correspondem a $87 \%$ do total, onde 60 proposições abordam questões relacionadas a pandemia e 27 não. Observa-se uma diferença significativa entre o volume de proposições apresentadas pelos dois poderes. Esse padrão, que demonstra o Legislativo com protagonismo no número de proposições, foi evidenciado pelo estudo de Tomio e Ricci (2012) e não se repete somente na Assembleia gaúcha, mas também outros Legislativos estaduais. Tal padrão é justificado segundo os autores pela existência de arranjos institucionais que diminuem os custos dos deputados ao apresentar uma proposição.

Em termos de aprovação dos projetos encaminhados, a tabela 2 apresenta as taxas de sucesso percebidas por cada um dos poderes no início da pandemia. 
Tabela 2 - Aprovações x encaminhamentos

Classificação Aprovados (a) Encaminhados (b) Taxa de sucesso (a/b)

Exec. Leg. Exec. Leg. Exec. Leg.

\begin{tabular}{lcccccc}
\hline Covid-19 & 8 & 9 & 8 & 60 & $\mathbf{1 0 0 \%}$ & $\mathbf{1 5 , 0 0 \%}$ \\
Outros temas & 5 & 2 & 5 & 27 & $\mathbf{1 0 0 \%}$ & $\mathbf{7 , 4 1 \%}$ \\
\hline Total & 13 & 11 & 13 & 87 & $\mathbf{1 0 0 \%}$ & $\mathbf{1 2 , 6 4 \%}$ \\
\hline
\end{tabular}

Fonte: Elaboração própria a partir dos dados da ALRS.

Quando verificado o comportamento das proposições oriundas do Poder Executivo, foi possível constatar uma taxa de aprovação absoluta. Essa aprovação foi independente da relação do conteúdo proposto com o enfrentamento da pandemia. As altas taxas de sucesso do Executivo gaúcho em relação ao Legislativo foram evidenciadas por Tomio e Ricci (2012), associando esses resultados não apenas aos arranjos institucionais que dão domínio da agenda legislativa ao governador, mas também pela existência de uma coalizão de apoio ao governo.

Outra comprovação da dominância do Poder Executivo ocorre a partir da análise da tramitação destas proposições: dos 13 projetos encaminhados, apenas 1 deles (8\%) foi efetivamente emendado pela $\mathrm{ALRS}^{10}$. Além disto, no que se refere à votação, a grande parte das proposições submetidas - 10 projetos $(77 \%)$ - recebeu votação favorável não apenas pelos partidos da base e daqueles que se consideram independentes, mas também pela totalidade dos deputados da oposição. Isto demonstra o quanto a produção oriunda do Poder Executivo não recebeu maiores críticas e restrições durante esse período mesmo quando apresentada aos parlamentares de fora da base do Governo ${ }^{11}$.

As pautas encaminhadas pelo Poder Legislativo, por sua vez, demonstraram baixas taxas de aprovação (13\%), com um percentual um pouco superior se considerarmos apenas aquelas relacionadas ao Covid-19 (15\%). Todavia, a análise de conteúdo das proposições originadas neste poder permitiu identificar que a totalidade das aprovações (11) esteve associada apenas àquelas encaminhadas pela Mesa Diretora (9) e por Comissões Específicas (2). Estas proposições, no entanto, refletem procedimentos de organização interna, que não têm

\footnotetext{
${ }^{10}$ PL 110/2020, referente às diretrizes orçamentárias para 2021. É importante ressaltar que, devido à natureza da matéria, este tipo de projeto é usualmente receptor de diversas emendas pelos parlamentares.

${ }^{11}$ Os 3 projetos que receberam votos contrários pela oposição foram os PLs 115, 116 e 124/2020. Nenhum deles foi
} 
impacto direto aos cidadãos. Pela Mesa, foram aprovados apenas projetos de decreto legislativo (5) para fins de reconhecimento de estado de calamidade pública e projetos de resolução (4) para regulamentar a própria atividade legislativa; pelas comissões, as proposições (2) estiveram associadas à aprovação de relatório e indicação de nome para compor agência estadual.

A elevada proporção de projetos não aprovados pelo Legislativo (87\%) deve ser analisada com cautela: devido ao curto período observado, desdobramentos podem ocorrer posteriormente. $\mathrm{O}$ contraste entre tempo de aprovação de matérias do Executivo frente às do Legislativo é um tópico já abordado pela literatura, sendo assim o contexto de pandemia aparentou não alterar esta dinâmica.

Com a finalidade de ilustrar os diferentes andamentos dos projetos, a próxima figura apresenta o curso das proposições - exclusivamente daquelas relacionadas ao tema 'Covid-19'.

Figura 2 - Tramitação das proposições relacionadas ao Covid-19 12.

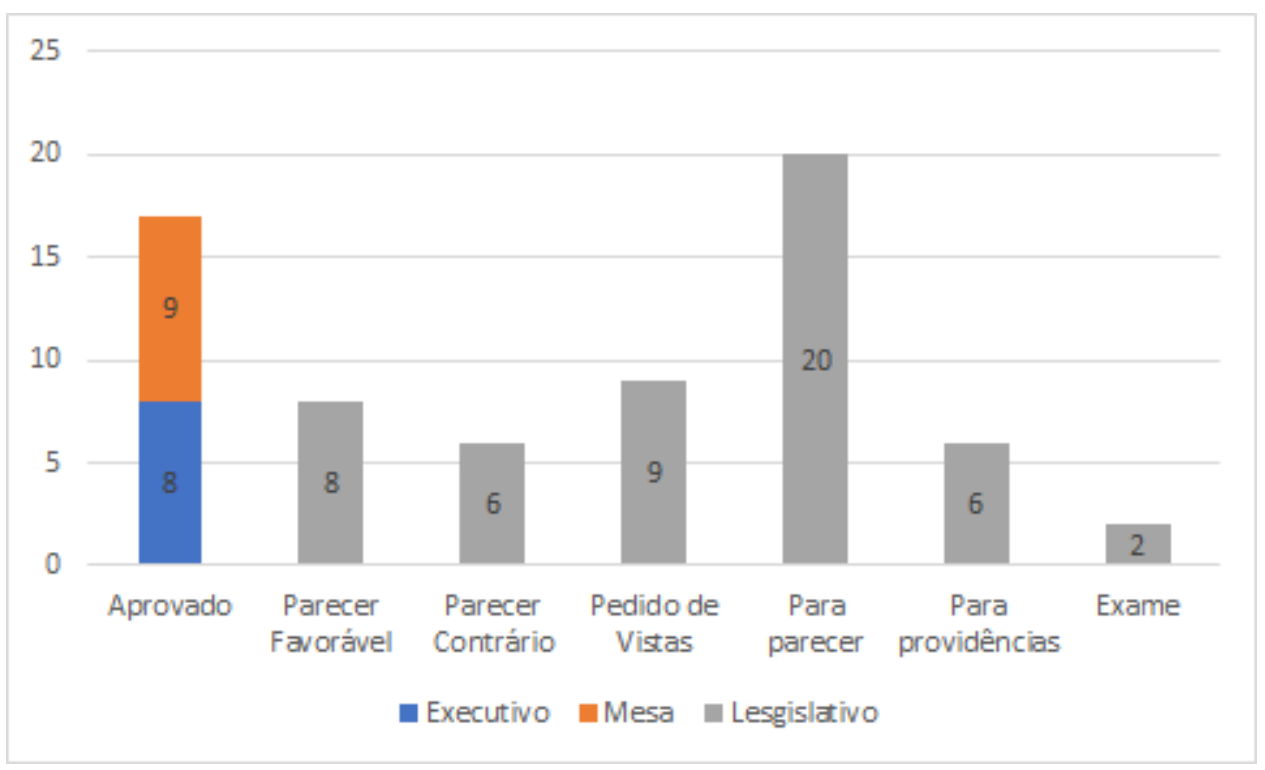

Fonte: Elaboração própria a partir dos dados da ALRS.

Os demais status de tramitação não permitem análises definitivas. Um parecer favorável em determinada data pode levar ao trâmite de pedidos de vistas posteriormente ou a situação de "para parecer" por meses. Desta forma, as informações contidas no gráfico são a título exclusivo de mapeamento do cenário dos projetos do Legislativo, não permitindo conclusões definitivas. A principal análise que se obtém desses dados é que dentro dos quatro primeiros meses, além da mesa gestora nenhum outro grupo ou deputado individual obteve sucesso nas proposições relacionadas ao Covid-19. Isso significa que propostas realizadas pelo Legislativo

relacionado ao tema 'Covid-19'.

12 Posição de tramitação até a data de 06/08/2020, conforme consulta no site da ALRS. 
em março, por exemplo, ainda estiveram no jogo de tramitação dentro da ALRS até início de agosto.

Para além da análise das tramitações nos primeiros meses do Covid-19, serão analisados com maior detalhamento os projetos relacionados à pandemia. Justifica-se essa escolha uma vez que o objetivo de estudo é compreender a atuação legislativa nesse contexto específico. Apesar do tema em comum, as proposições abordam a pandemia em diferentes aspectos, sendo necessário classificar seu conteúdo para operacionalizar a análise. Diferentemente de classificações que enfocam a distribuição de benefícios na dimensão territorial, tal como a proposta por Ricci (2002), as tipologias aqui utilizadas buscam evidenciar as diferentes respostas dadas no combate à pandemia.

Tabela 3 - Quantidade de proposições por tipologia

\begin{tabular}{lccccc}
\hline \multicolumn{1}{c}{ Tipologia } & Março & Abril & Maio & Junho & Total \\
\hline $\begin{array}{l}\text { Medidas de } \\
\text { Prevenção }\end{array}$ & - & 3 & 8 & 1 & $\mathbf{1 2}$ \\
$\begin{array}{l}\text { Profissionais da } \\
\text { Saúde }\end{array}$ & 2 & 4 & 1 & - & $\mathbf{7}$ \\
$\begin{array}{l}\text { Proteção Social } \\
\text { Setor Privado }\end{array}$ & 4 & 7 & 15 & 1 & $\mathbf{2 7}$ \\
Administrativo & 3 & 6 & 6 & 2 & $\mathbf{1 7}$ \\
\hline Total & $\mathbf{9}$ & $\mathbf{2 0}$ & $\mathbf{3 3}$ & $\mathbf{6}$ & $\mathbf{6 8}$ \\
\hline
\end{tabular}

Fonte: Elaboração própria a partir dos dados da ALRS.

Foi possível observar que, dentre as proposições encaminhadas para o combate ao Covid-19, grande parte esteve relacionada à temas de proteção social (40\%), seguida das matérias administrativas (25\%) e das medidas de prevenção (18\%). Também foi possível notar o surgimento, a partir de maio, de proposições associadas ao retorno da atividade econômica por meio de proteção ao setor privado. 
Figura 3 - Projetos pautados na ALRS classificados por poder proponente e tipologia.

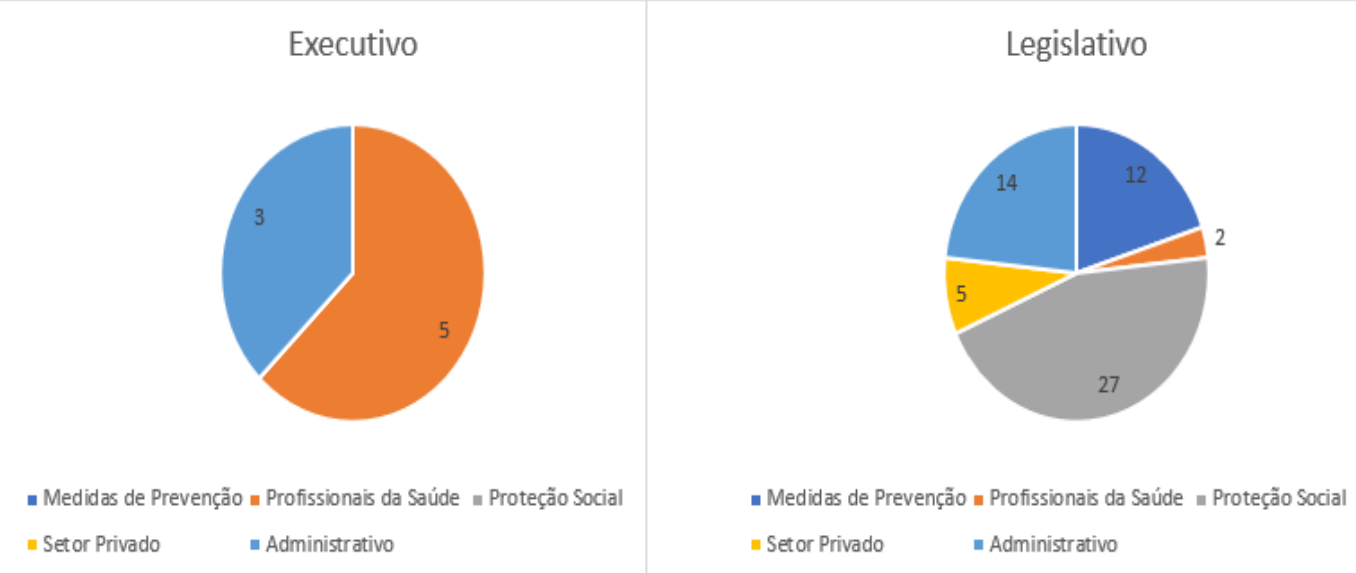

Fonte: Elaboração própria a partir dos dados da ALRS.

Quando observadas as temáticas propostas de acordo com o poder que as colocou em pauta, surgem algumas questões. A concentração do Executivo em apenas dois temas dos cinco identificados é uma manifestação deste poder sobre as medidas que precisam ser aprovadas pelo Legislativo. Um exemplo é a contratação emergencial de profissionais de saúde, que compõe a maioria de suas proposições e pode ser justificado pela necessidade de adequar as estruturas de atendimento em saúde à pandemia. Apesar de não submeter à ALRS nenhuma medida de prevenção, o Poder Executivo instituiu o Modelo de Distanciamento Social Controlado. Essa política regula, desde maio, a abertura de estabelecimentos e circulação da população via decreto. Em geral, o Executivo se relaciona com o Legislativo com medidas que por regramento institucional necessitem de aprovação; no mais lança mão de outros meios - tais como decretos - para coordenar a ação estadual durante a pandemia.

No que se refere à dimensão partidária, foi possível constatar diferenças de perfis de interesse quanto ao conteúdo das proposições encaminhadas pelo Poder Legislativo durante os quatro primeiros meses da pandemia ${ }^{13}$.

\footnotetext{
${ }^{13}$ Para melhor ilustração quanto às diferenças de atuação no contexto partidário da ALRS, a análise desconsidera os encaminhamentos realizados diretamente pelo Poder Executivo, Mesa Gestora e Comissões, bem como recupera o conjunto total das proposições, relacionadas ou não ao Covid-19. Desta forma, foi possível encontrar 72 proposições passíveis de análise quanto ao aspecto partidário.
} 
Figura 4 - Projetos pautados na ALRS classificados por grupo partidário proponente e tipologia

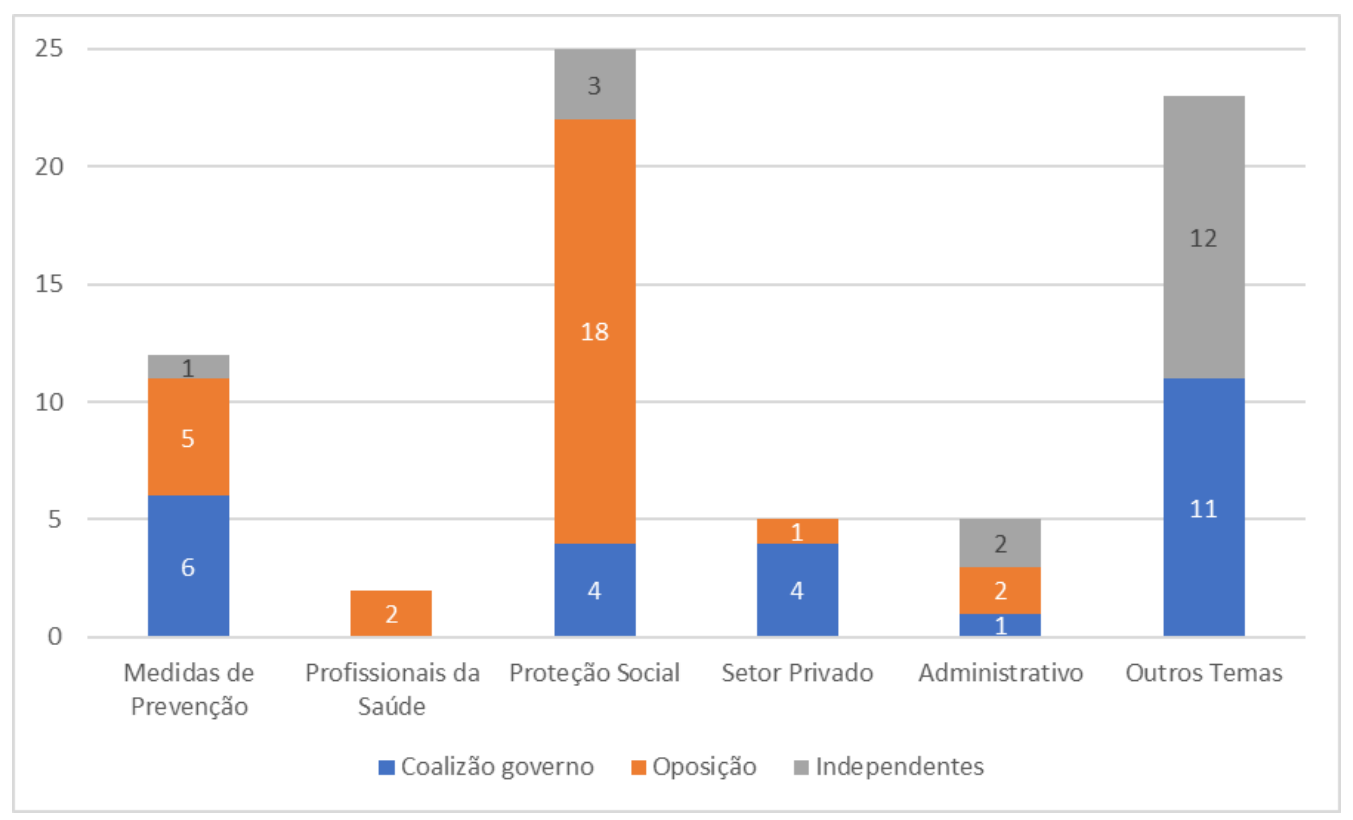

Fonte: Elaboração própria a partir dos dados da ALRS.

Na dimensão da atuação dos partidos no Legislativo, a oposição teve como pauta dominante a proteção social (64\%). Este comportamento reflete a agenda partidária esperada no contexto político da ALRS, privilegiando a proteção de setores de menor renda ou de segmentos específicos aos impactos econômicos da crise, bem como uma possível intencionalidade de comunicação com o seu eleitorado-base. As proposições encaminhadas pelos partidos que possuem secretarias e por aqueles que se declaram independentes teve menor participação relativa no total dos projetos relacionados ao Covid-19 (43\%, frente a 57\% da oposição). Esses também tiveram maior representatividade no conjunto de proposições relacionadas à retomada da atividade econômica por meio de proteção às atividades do setor privado $(80 \%$ de participação nesta tipologia). Importante notar que a oposição não pautou projetos fora do escopo da pandemia durante o período analisado. Dentre os projetos de outros temas, a participação foi similar entre a coalizão e os partidos independentes.

\section{Considerações Finais}

No escopo do estudo é válido ressaltar as limitações dos achados aqui identificados. O período permite avaliar a primeira reação da ALRS em relação à pandemia. Os desdobramentos desse contexto que perdurará, ao menos a médio prazo, devem ser avaliados com atenção. Ao analisar o volume de proposições apresentadas, o Legislativo gaúcho apresenta entusiasmo ao propor novas ações em relação ao Executivo. Isso, no entanto, não se reflete em projetos que de fato são aprovados e impactam a conjuntura. Por outro lado, as poucas proposições do 
Executivo apresentam absoluta taxa de sucesso. Esse comportamento da ALRS é similar à conduta identificada por outros estudos (TOMIO; RICCI, 2012), indicando que o choque exógeno apresentado pela pandemia aparentemente não gerou grandes mudanças na relação entre os poderes, ao menos nos primeiros meses desse novo contexto. Considerando as prerrogativas de ação estadual em contexto de calamidade, o poder Executivo pode ter expandido sua capacidade de implementação de agenda, no entanto um estudo de maior horizonte temporal permitirá realizar tal análise com maior precisão.

Como comentado, o poder Executivo vem instituindo, por meio de decretos, a política estadual de medidas de contenção da propagação do vírus. Dessa forma, abordar projetos sobre medidas de prevenção na ALRS não aparenta ser uma necessidade. O Legislativo por sua vez apresenta projetos que se sobrepõem à ação do Executivo. Projetos que sugerem limitação de passageiros no transporte público, por exemplo, versam sobre medidas que há muito já estão instituídas nos protocolos decretados pelo poder Executivo. Sendo assim, apesar de esses projetos seguirem em tramitação, a sua aprovação já não possui relevância ao combate da pandemia.

Ainda em referência aos projetos propostos pelos deputados, ressalta-se que a oposição apresenta comportamento distinto dos demais partidos, visto que continua mantendo o seu posicionamento partidário - perceptível pela análise do tema dos projetos apresentados demonstrando uma preocupação maior em relação a 'proteção' social' e em segundo lugar relacionados a 'medidas de prevenção'. Esse comportamento guarda relação de contraposição com a precedente agenda, implementada pelo governo, de reformas que visam a contenção de gastos.

O panorama estadual, durante os primeiros meses da pandemia, pode ser resumido em um Executivo coordenando a ação por meio de todas as suas ferramentas. Entre seus meios de implementação de agenda está inclusa a aprovação de projetos no Legislativo, onde não se identifica resistência. Nesse sentido, cabe sugerir futuros estudos que contemplem períodos mais abrangentes para analisar se esse padrão permanece ao longo do tempo de duração da pandemia.

\section{Referências}

ABRANCHES, Sérgio. Presidencialismo de coalizão: o dilema institucional brasileiro. Dados, v. 31, n. 1, p. 5-38, 1988.

ABRANCHES, Sérgio. Presidencialismo de coalizão: raízes e evolução do modelo político brasileiro. São Paulo: Editora Companhia das Letras, 2018.

ABRUCIO, Fernando Luiz. Os barões da federação: os governadores e a redemocratização brasileira. São Paulo: Editora Hucitec, 1998. 
ALMEIDA, Acir. A produção legislativa no pós-1988: tendências recentes e desafios. 2014.In: MONASTERIO, Leonardo Monteiro; NERI, Marcelo Côrtes; SOARES, Sergei Suarez Dillon. Brasil em desenvolvimento 2014: estado, planejamento e políticas públicas. Brasília: IPEA, 2014. v. 2

ALMEIDA, Acir. Processo legislativo: mudanças recentes e desafios. Brasília: IPEA, 2015.

AMORIM NETO, Octavio et al. Formação de gabinetes presidenciais no Brasil: coalizão versus cooptação. Nova Economia, v. 4, n. 1, p. 9-34, 1994.

AMORIM NETO, Octavio. Gabinetes presidenciais, ciclos eleitorais e disciplina legislativa no Brasil. Dados, v. 43, n. 3, p. 479-519, 2000.

ANASTASIA, Fátima. Transformando o legislativo: a experiência da Assembleia Legislativa de Minas Gerais. In: O PODER Legislativo nos Estados: diversidade e convergência. Rio de Janeiro: Editora FGV, p. 23-83, 2001. $\begin{array}{lllr}\text { ASSEMBLEIA } & \text { LEGISLATIVA DO ESTADO DO RIO GRANDE DO SUL. Pesquisa de } \\ \text { Proposições } & \text { Legislativas, } & 2020 . & \text { Disponível }\end{array}$ http://www.al.rs.gov.br/legislativo/Proposicoes.aspx. Acesso em: 7 ago. 2020.

BLANCHARD, O. Macroeconomia. Rio de Janeiro: Pearson Brasil, 2011.

COCKERHAM, Alexandra G.; CREW JR, Robert E. The Covid-19 pandemic shows the power and limits of American federalism. USApp-American Politics and Policy Blog, 2020.

FERREIRA, Débora Costa; MENEGUIN, Fernando Boarato; BUGARIN, Maurício Soares. Atuação do poder legislativo estadual: análise dos incentivos dos deputados estaduais na atividade legislativa. REI: -Revista Estudos Institucionais, v. 4, n. 2, p. 700-724, 2018.

FIGUEIREDO, Argelina Cheibub; LIMONGI, Fernando de Magalhaes Papaterra. Executivo e Legislativo na nova ordem constitucional. Rio de Janeiro: Editora FGV, 1999.

FIGUEIREDO, Argelina; LIMONGI, Fernando Bases institucionais do presidencialismo de coalizão. Lua Nova: Revista de Cultura e Política, n. 44, p. 81-106, 1998.

FIGUEROA C, CASTILLO EG, NORQUIST G, et al. A Window of Opportunity: Visions and Strategies for Behavioral Health Policy Innovation Ethnicity \& disease, n. 28, p. 407-416, 2018. Disponível em: https://www.ncbi.nlm.nih.gov/pmc/articles/PMC6128330/. Acesso em: 10 set. 2020

GROHMANN, Luis Gustavo Mello. O processo legislativo no Rio Grande do Sul: 1995 a 1998. In: SANTOS, Fabiano. O Poder Legislativo nos estados: diversidade e convergência. Rio de Janeiro: Editora da FGV, 2001.

JANSEN Marijn, VOOR Haiko. Agile and adaptive governance in crisis response: Lessons from the COVID-19 pandemic. International Journal of Information Management v. 55, out. 2020. Disponível em: https://doi.org/10.1016/j.ijinfomgt.2020.102180. Acesso em: 10 out. 2020.

LUZ, Joyce; AFLALO, Hannah Maruci; DUTRA, Ana Beatriz.A. Relação Executivo Legislativo Revisitada: A governabilidade da coalizão no Brasil. In: DANTAS, Humberto. Governabilidade. Rio de Janeiro: Konrad Adenauer Stiftung, 2018. 
MAYER, Rodrigo. Como os governos estaduais lidam com a pandemia. Nexo Jornal, 2020. Disponível em: https://www.nexojornal.com.br/especial/2020/05/10/Como-os-governosestaduais-lidam-com-a-pandemia. Acesso em: 10 set. 2020.

NUNES, Felipe. Coalizões legislativas estaduais: uma análise comparativa dos governos de Minas Gerais e Rio Grande do Sul entre 1998-2006. Revista Teoria \& Sociedade, v. 1, n. 1, p. 40-78, 2011.

NUNES, Felipe. Os determinantes dos resultados de soma positiva em Minas Gerais e no Rio Grande do Sul. Revista de Sociologia e Política, v. 21, n. 47, p. 91-112, 2013.

OLIVEIRA, Augusto Neftali Corte de. Desafios políticos do Rio Grande do Sul: a decisividade do Governador. Indicadores Econômicos FEE, v. 43, n. 4, p. 135-148, 2016 a.

OLIVEIRA, Augusto Neftali Corte de. Os Sistemas Partidários do Rio Grande do Sul: do Império à Nova República. Rev. Bras. Ciênc. Polít., Brasília , n. 25, p. 87-132, jan. 2018.

OLIVEIRA, Augusto Neftali Corte de. Partidos e coalizões no Rio Grande do Sul: questões de governabilidade e representatividade. Indicadores Econômicos FEE, v. 44, n. 2, p. 79-92, 2016 b.

PRATTI, Luana Puppin; ARAÚJO, Paulo Magalhães. Deputados do Espírito Santo: Perfil socioeconômico e trajetória política, 1987-2011. E-Legis: Revista Eletrônica do Programa de Pós-Graduação da Câmara dos Deputados, Brasília, v. 12, n. 28, p. 113-144, jan./abr. 2019.

QUINTÃO, Thales Torres; CUNHA, Eleonora Schettini Martins. Fala que eu te escuto: Ouvidorias parlamentares e o seu potencial democrático. Revista de Sociologia e Política, v. 26, n. 66, p. 125-143, 2018.

RICCI, Paolo. A medida das leis: do uso de noções genéricas à mensuração do imponderável. Revista Brasileira de Informação Bibliográfica em Ciências Sociais, São Paulo, n. 54, p. 101-123, 2002.

SANTANA, Luciana; PEREZ, Olívia Cristina. Os governos estaduais e as ações de enfrentamento à pandemia no Brasil. Nexo Jornal, 2020. Disponível em: https://www.nexojornal.com.br/especial/2020/05/10/Como-os-governos-estaduais-lidam-com-apandemia. Acesso em: 7 ago 2020.

SCHNEIDER, Howard. Will the coronavirus cause a depression in the US? The World Economic Forum COVID Action Platform, 2020. Disponível em: https://www.weforum.org/agenda/authors/howard-schneider. Acesso em: 20 jun. 2020.

TOMIO, Fabrício Ricardo de Limas. Federalismo, municípios e decisões legislativas: a criação de municípios no Rio Grande do Sul. Revista de Sociologia e Política, n. 24, p. 123-148, 2005.

TOMIO, Fabrício Ricardo de Limas; RICCI, Paolo. O governo estadual na experiência política brasileira: os desempenhos legislativos das assembleias estaduais. Revista de Sociologia e Política, v. 20, n. 41, p. 193-217, 2012.

WEIBLE, Christopher M. et al. COVID-19 and the policy sciences: initial reactions and perspectives. Policy sciences, p. 1-17, 2020.

ZORZAL, Gabriela; CARLOS, Euzeneia. Audiências públicas do Legislativo estadual: fatores endógenos e exógenos na análise da efetividade da participação. Revista de Sociologia e Política, v. 25, n. 64, p. 23-46, 2017. 